\title{
A Mini Review on Challenges in Regulatory, Development and Clinical Development for Herbal Product
}

\author{
"1,2 Param Bhakti healthcare \& Research in affiliation with Param Healthcare \& IT Services, Iselin, New \\ Jersey USA
}

\author{
Article Info \\ Volume 3 Issue 6 \\ Page Number: 50-54
}

Publication Issue :

November-December-2020

\section{Article History}

Accepted : 01 Dec 2020

Published : 25 Dec 2020

\begin{abstract}
A review of the regulatory status of herbal drugs/products was done for few countries forming part of Asia, Africa, America, Europe, and Australia, to understand various categories under which the trade of herbal products is permitted and their premarketing requirements. A critical assessment was done, to know the hindrances in the process of harmonization of herbal products. It has been found that there is a lack of harmonization in the regulatory requirements of herbal products internationally, besides the issues of availability of herbs and their conservation. These are hindering the international trade and growth of the herbal products segment. Different challenges and regulatory guidelines discussed for the clinical trial of herbal drugs will be useful for various industries for considering it before going ahead for clinical trial of their product. This mini review explore the various country herbal drug clinical trial procedures and potential.
\end{abstract}

Keywords: Herbal Drugs, Clinical Trials, Regulatory

\section{Introduction}

Herbal medicines have been used in traditional medical practices for centuries; however, the development of herbal medicine within an evidencebased medicine's framework is relatively new. Demonstrating the safety and efficacy of such medicines is fraught with challenges and criticisms, especially when compared with "Western chemical medical compounds." While practitioners of herbal medicine are often not only comfortable with the application of such medicines but also largely convinced by the results they experience with patients, the scientific validity of herbal medicines in research and development is still often questioned. This is partly due to the application of similar methodologies across dissimilar medical products as well as to a lack of quality control and product standardization. The application of contemporary evidence-based approaches, particularly controlled clinical trials, has presented specific challenges and issues for herbal medicines in R\&D. There is a need to follow the acceptable standards in the conduct of herbal medicine R\&D, while also taking into account the complexity of the chemical composition of herbal medicines and their use in the framework of traditional medical practices. Research design and the conduct of research must be scientifically and 
ethically sound, while also accounting for the medical philosophies and practices that accompany the use of traditional medicines.

International Trade of Herbal Drugs is subject to compliance with the International treaties like Convention on International Trade in Endangered Species of Wild Fauna and Flora (CITES). CITES, who regulate the international trade of certain species, which are threatened with extinction or which would be reaching the status of being endangered, if their overexploitation is not checked. Internationally, herbal products are regulated under different classifications, some of which are: Complimentary medicines, Natural health products, Prescription medicines, over the counter medicines, Supplements, Traditional herbal medicines, etc. The regulatory requirements of these vary considerably. While prescription medicines are strictly regulated, the extent of control on supplements is relatively low [1-3].

\section{REGULATORY OVERVIEW}

\section{A. India}

Herbal drugs are regulated under the Drug and Cosmetic Act (D and C) 1940 and Rules 1945 in India, where regulatory provisions for Ayurveda, Unani, Siddha medicine are clearly laid down. Department of AYUSH is the regulatory authority and mandate that any manufacture or marketing of herbal drugs have to be done after obtaining manufacturing license, as applicable.

\section{B. Philippines}

The herbal medicines are regulated in the Philippines as traditionally used herbal products. The regulators require that the preparations from plant materials, whose claimed application is based only on traditional experience of long usage, which should be at least five or more decades as documented in medical, historical, and ethnological literatureare permitted to be marketed under this category.

\section{Nigeria}

In Nigeria, the trade of herbal products is regulated by National Agency for Food and Drug Administration and Control (NAFDAC) who has classified these products as "Herbal Medicines and Related Products." Premarketing registration of herbal medicines and related products is mandatory in Nigeria.

\section{Saudi Arabia}

Herbal products are classified in Saudi Arabia as traditional products. They are allowed if they have at least 50 consecutive years of traditional use. Their dose and the method of preparation must be same as those used, traditionally. According to the evidence provided, they may fall under the sub-categories: Pharmacopoeial evidence for traditional products, Nonpharmacopoeial evidence for traditional products.

\section{E. Australia}

Therapeutic Goods Administration, the regulatory agency of Australia, regulate herbal products under the category of complementary medicine. Ayurvedic medicine, traditional Chinese medicine, and Australian indigenous medicines are all covered under this category.

\section{F. United States of America}

The botanical products are classified as a drug, food or a dietary supplement by the United States Food and Drug Administration on the basis of the claims or end use. A product that is used to prevent, diagnose, mitigate, treat or cure a disease would fall 
under the category of drug. If the intended use of a botanical product is to affect the structure or function of the human body, it may be classified as either a drug or a dietary supplement. As per FDA, the drug must be marketed under an approved New Drug Application (NDA).

FDA regulates the dietary supplements under the Dietary Supplement Health and Education Act of 1994. These do not require premarket approval and it's the responsibility of the marketer to ensure the safety and labeling compliance of their products with the regulations. The claims need to comply with the regulatory guidelines issued by the FDA. The manufacturing of dietary supplements should be done as per the current GMP for dietary supplements.

\section{G. Canada}

Since January 1, 2004, Health Canada regulates herbal remedies and traditional medicines such as Ayurvedic medicine, under the natural health products regulations. The regulations mandate that a manufacturer, packer, labeler or importer need to have a prior registration with Health Canada before commencing any such activity $[4,8-12]$.

\section{Scope of herbal medicine clinical trials}

Traditional/Herbal products have always been an important part of the public's healthcare around the world. In recent years, world has witnessed the increasing growth in popularity of over-the-counter (OTC) health foods, nutraceuticals and medicinal products from plants or other natural sources in developed as well as developing countries. During the past decades, public interest in natural therapies, namely herbal medicine, has increased dramatically not only in developing countries but also in industrialized countries. This has renewed and rejuvenated the international trade in herbal medicine enormously and has attracted most of the pharmaceutical companies, including the multinationals8. This new drive of phytotherapeutic market is due to a number of factors like preference of consumers for natural therapies; concern of consumer regarding undesirable side effects of modern medicines, since millions of people all over the world have been using herbal medicines for thousands of years; some traditional/conventional therapies, where treatment paradigm is quite slow, psychologically patient finds solace in herbals; freedom and tendency towards self-medication; revival of trust and faith due to steps taken by regulatory authorities for improvement in quality, proof of efficacy and safety of herbal medicines and relatively high cost of synthetic medicines $[4,5]$.

\section{Major Problems and Challenges with Clinical Trials of herbal drugs}

Due to the fact that plants cannot be patented, minimal research has been carried out for their role as medicinal agents. In USA the process of demonstrating drug safety and efficacy of a new pharmaceutical product takes approximately 15 years and costs an estimated USD 2.5 billion and only few research companies are willing to fully invest the time and money necessary to satisfy the FDA requirements. The regulatory requirements for proof of safety and efficacy generally make it uneconomical for the private industry to conduct costly clinical trials on herbal medicine. If, however, the regulatory requirements regarding safety and efficacy can be made a bit relaxed, private companies might pursue research more easily for safety and quality control of herbal medicine. So a considerable amount of public fund might still however be 
required to confirm the validity of herbal remedies, because pharmaceutical, companies would earn meager incentive to develop a, herbal product that might displace or replace a patented, drug. So it is very important to generate more data to assess the efficacy than to assess safety of herbal medicine and, for proof of efficacy, the clinical trial has become the gold standard to majority of population. It is a fact that unless a proper study has been conducted on human subjects, no pertinent and appropriate conclusion on its efficacy and or safety can be drawn. Further, the infrastructure for alternative and herbal medicine research is largely nonexistent in developing countries that add fuel to the fire. Ayurvedic Herbal Medicinal Products (HMPs) are widely marketed as dietary supplements in different countries [6,7].

\section{Conclusion}

Factors such as growing trend of consumer acceptance of herbal products for healthcare, beauty care and diet supplementation, globally, focus of researchers and pharmaceutical industry on herbal sector for economical reasons, and more and more countries according legal status to herbal products and permitting legalized trade of these products in their countries indicate growth opportunity for herbal products. However, challenges like developing globally acceptable products due to differences in regulatory requirements related to quality, safety and efficacy data, differences in the status of ingredients and excipients are hindering the growth of herbal drug industry. A uniform research policy in herbal medicines is need of the hour. The goals of these suggestions are to facilitate the scientific evaluation and the eventual integration of traditional medicine into the national healthcare system, critically assisting an eventual rational use of traditional medicine through development of technical guidelines and international standards.

\section{References}

1. Bhatt P, Fnu G, Bhatia D, Shahid A, Sutariya V. Nanodelivery of Resveratrol-Loaded PLGA Nanoparticles for Age-Related Macular Degeneration. AAPS PharmSciTech. 2020; 21(8):291.

2. Tandel H, Bhatt $P$, Jain K, Shahiwala A, Misra A. In-Vitro and In-Vivo Tools in Emerging Drug Delivery Scenario: Challenges and Updates.In: Misra ASA, editor. In-vitro and invivo tools in drug delivery research for optimum clinical outcomes. Boca Raton: CRC Press; 2018.

3. Chaudhary R, Chandrashekharan M, Mishra S. Embryotoxicity and teratogenicity studies of an ayurvedic ontraceptives-pippalyadi vati. J Ethnopharmacol. 2001; 74: 189-93.

4. Mills S. Herbal medicine. In: Lewith GT, Jonas WB, Walach $\mathrm{H}$, editors. Clinical Research in Complementary herapies: Principles, Problems and Solutions. Elsevier Science: 2003; p. 211-27.

5. Howard KL, Orlinsky DE, Perilstein J. Contribution of therapist's to patient's experiences in psychotherapy: a components of variance model for analyzing process data. J Consult Clin Psychol. 1976; 44: 520-6.

6. Mills S. Clinical Research in Complementary Therapies: Principles, Problems and Solutions. In: Lewith GT, Jonas WB, Walach H, editors. Elsevier Science: Churchill Livingstone; 2003. pp. 211-27.

7. Bansal D, Hota D, Chakrabarti A. Research methodological issues in evaluating herbal interventions. J Clin Trial. 2010;2:15-21. 
8. Eisenberg DM, Kessler RC, Foster C, Norlock FE, Calkins DR, Delbanco TL. Unconventional medicine in the United States. Prevalence, costs, and patterns of use. $\mathrm{N}$ Engl J Med. 1993;328:246-52.

9. Geneva, Switzerland: 2014. [Last cited on 2014 Apr 29]. Convention on International Trade in Endangered Species of Wild Fauna and Flora. Available from: http://www.cites.org/eng/disc/what.php

10. Geneva: WHO Library Cataloguing-inPublication Data, World Health Organization; 2005. [Last cited on 2014 Apr 29]. Guidelines on the Registration of Traditionally used Herbal Products, Department of Health, Republic of Philippines, Report of a WHO Global Survey. Available from: http://www.apps.who.int/medicinedocs/p df/s7916e/s7916e.pdf

11. Food and Drug Administration. Rockville: U.S. Department of Health and Human Services, Center for Drug Evaluation and Research (CDER): Guidance for Industry, Botanical Drug Products Online Resource. 2004. [Last cited on 2014 Apr 29]. Available from: http://www.fda.gov/cder/guidance/index. htm

12. Official Journal of the European Union: Directive 2004/24/EC; 31st March. 2004. [Last cited on 2014 Apr 29]. Available from: http://www.eurlex.europa.eu/LexUriServ/LexUriServ.do?uri=OJ : L: 2004:136:0085:0090:en: PDF . 